\title{
Chronic intrathoracic gastric volvulus
}

\author{
M P Senanayake ${ }^{1}$, P V Dissanayake ${ }^{2}$, G Kumarasinghe ${ }^{2}$, I N A Goonaratne ${ }^{3}$, A Lamahewage ${ }^{4}$
}

We report an infant with chronic intrathoracic mesenteroaxial gastric volvulus in whom the diagnosis was delayed for several months. This case highlights the need for considering this entity in infants and young children with recurrent vomiting.

\section{Case report}

A one year old boy presented with recurrent, episodic, non-bilious vomiting and severe growth failure starting at age three months when exclusively breast fed. Vomiting lasted one to two days and was accompanied by crying, irritability and poor feeding without fever, constipation or diarrhoea. In between episodes he was well. Urinary infection, metabolic, renal or hepatic dysfunction and malrotation had been excluded. He was emaciated and dehydrated. Head circumference, skin colour and genitalia were normal. There was no organomegaly or developmental delay. Chest $\mathrm{X}$ ray showed an elevated left hemi diaphragm (Figure 1). Upper gastrointestinal contrast study showed the stomach herniated into thorax and placed upside down. Pylorus, antrum and distal body were situated superior to cardia with partial obstruction of duodenum (Figure 2).

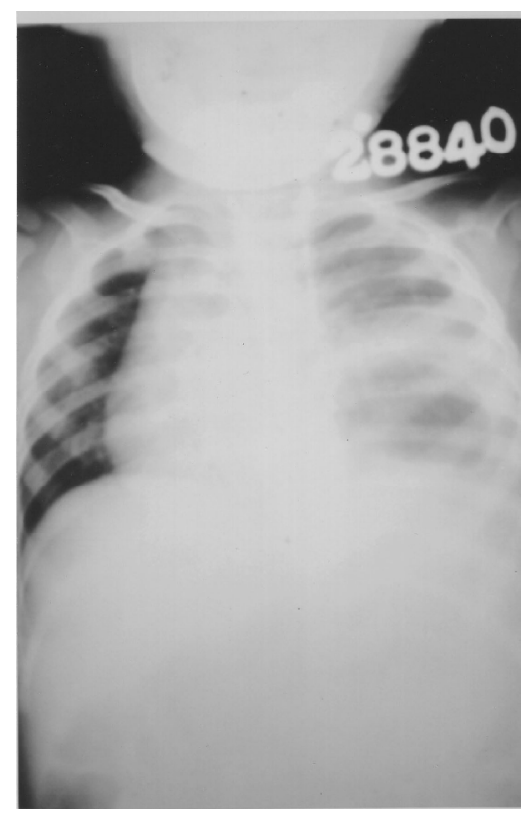

Figure 1. Plain $X$ ray chest: Elevated left dome of diaphragm and soft opacity with lucency in left lower chest.

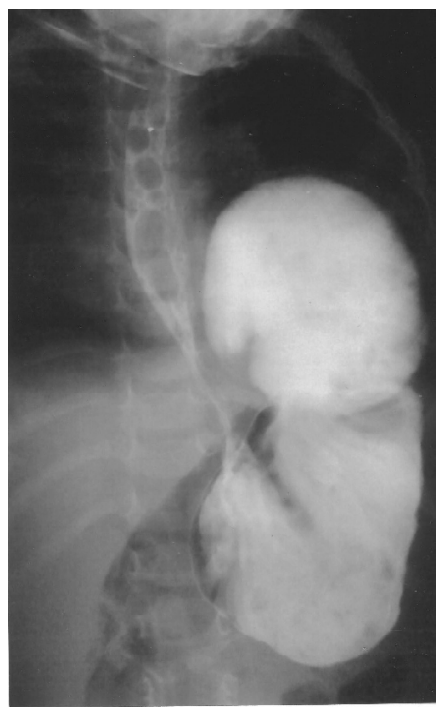

Figure 2. Upper GI contrast study (AP view) - Gastric cardia in abdomen, antrum and pylorus in chest, ("an upside down stomach" suggestive of mesenteroaxial volvulus of stomach).

Diagnosis of mesenteroaxial gastric volvulus and posterior diaphragmatic hernia (Bochdalek type) were made. At surgery the intra thoracic gastric volvulus was reduced, diaphragmatic defect repaired and anterior gastropexy performed. He stopped vomiting and started thriving normally.

Gastric volvulus is rare but in children, the chronic form is commoner $[1,2]$. In the absence of gut ischaemia, perforation or haemorrhage physical signs are minimal. [3]. Our patient demonstrates how ultrasound examination and thoracoabdominal X rays can be misleading. Upper gastrointestinal contrast study provided a definitive diagnosis and differentiated mesenteroaxial from organoaxial volvulus.

\section{References}

1. Miller DL, Pasquale MD, Seneca RP, Hodin E. Gastric volvulus in the pediatric population. Archives of Surgery 1991; 126: 1146-9.

2. Oh SK, Han BK Levin TL, Murphy R,Blitman NM, Ramos C. Gastric volvulus in children: The twists and turns of an unusual entity. Pediatric Radiology 2008; 38: 297-304.

3. Cribbs RK, Gow KW, Wulkan ML. Gastric volvulus in infants and children. Pediatrics 2008; 122: 752- 62. ${ }^{1}$ Department of Paediatrics, University of Colombo, Sri Lanka, ${ }^{2}$ Department of Paediatrics, ${ }^{3}$ Radiology and ${ }^{4}$ Paediatric
Surgery, Lady Ridgeway Hospital for Children, Colombo, Sri Lanka.

Correspondence: MPS, e-mail <manouri.senanayake@gmail.com>. Received 15 October 2009 and revised version accepted 15 March 2010. Competing interests: none declared. 